\title{
Delayed Dispersal and Immigration in Equatorial Sakis (Pithecia aequatorialis): Factors in the Transition from Pair- to Group-Living
}

\author{
Amy M. Porter ${ }^{a}$ Mark N. Grote ${ }^{a}$ Lynne A. Isbell ${ }^{a} b$ \\ Eduardo Fernandez-Duque ${ }^{c, f}$ Anthony Di Fiore ${ }^{d, e}$ \\ ${ }^{a}$ Department of Anthropology and ${ }^{b}$ Animal Behavior Graduate Group, University of \\ California, Davis, CA, 'Department of Anthropology, Yale University, New Haven, CT, \\ ${ }^{\mathrm{d}}$ Department of Anthropology, University of Austin at Texas, Austin, TX, and \\ e Center for the Study of Human Origins, Department of Anthropology, New York University,

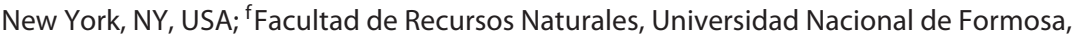 \\ Formosa, Argentina
}

\author{
Keywords \\ Saki monkeys · Male immigration · Mate replacement · Delayed dispersal · \\ Log odds ratio
}

\begin{abstract}
Saki monkeys (Pithecia spp.) live in pairs and small groups, sometimes with more than 1 same-sex adult. Previous studies have not been able to distinguish additional, unrelated adults from adult-sized offspring, but both can influence social relationships and mating strategies, albeit in different ways. In this study, we documented the immigration of an adult male equatorial saki ( $P$. aequatorialis) into a group following the departure of the previous resident male. At immigration, the group contained an adult female, her 5-year-old (adult age) and 1.5-year-old daughters, and her 1-month-old infant. We used nearest neighbor, approach, grooming, playing, aggression, and copulation data to describe the social dynamics between the immigrant male and the 2 adult females. In the 12 months following his arrival, the immigrant male tended to be closer to and groom the adult daughter more than the mother, but he mated with both females. Both females interacted more with the immigrant male than with each other, and both females eventually reproduced. These observations provide evidence that in equatorial sakis, adult offspring may delay dispersal and reproduce within their natal group, thus transitioning from groups of reproductive pairs to groups with more than 1 reproductive adult of the same sex.

(c) 2017 S. Karger AG, Basel
\end{abstract}

\begin{tabular}{|c|c|c|}
\hline KARGER & (C) 2017 S. Karger AG, Basel & $\begin{array}{l}\text { Lynne A. Isbell } \\
\text { Department of Anthropology, University of California }\end{array}$ \\
\hline $\begin{array}{l}\text { E-Mail karger@karger.com } \\
\text { www.karger.com/fpr }\end{array}$ & & $\begin{array}{l}\text { One Shields Ave. } \\
\text { Davis, CA } 95616 \text { (USA) } \\
\text { E-Mail laisbell@ ucdavis.edu }\end{array}$ \\
\hline
\end{tabular}




\section{Introduction}

Pair-living primates were once viewed as having relatively simple social relationships, in part because animals in small family groups are perceived to have more limited opportunities for developing complex social networks than animals living in larger groups [Kinzey, 1987]. However, closer examination of the social lives of pairliving animals suggests that this need not be the case. For example, pair members are sometimes observed to interact frequently with extra-group individuals, including engaging in extra-pair copulations [Birkhead et al., 1995; Cohas et al., 2007; Jones et al., 2012; Barelli et al., 2013; Bonadonna et al., 2014]. Interactions with extra-group individuals can also result in turnover of resident adults within pairs, through either replacement by floaters (i.e., solitary individuals without a territory) or by "divorce" as a pair member leaves a group to pursue new mating opportunities elsewhere [Palombit, 1994; Choudhury, 1995; Ens et al., 1996; Otter and Ratcliffe, 1996; Morton et al., 2000; Lardy et al., 2010; Fernandez-Duque and Huck, 2013; Pérez-Staples et al., 2013; Porter et al., 2015]. Occasionally, putatively unrelated animals also immigrate into established groups and remain as additional breeding adults [Davies, 1992; Palombit, 1994; Brockelman et al., 1998; Seddon et al., 2003; Lappan, 2007], thus changing a social system from pair-living to group-living.

The transition from pair-living to group-living can also occur through retention of mature offspring. Generally in pair-living primates, offspring of both sexes disperse once they reach sexual maturity, either leaving voluntarily or being forced out by their same-sex parent [Tilson, 1981; Wolff, 1993; Isbell, 2004]. It has been suggested that this is ultimately a function of food resource availability: if resources cannot support multiple breeding adults, then parents will compete with their offspring and either evict them or reproductively suppress them [Emlen, 1995; Isbell, 2004; Digby et al., 2011]. Conflict over breeding status following a parent's replacement has been reported in birds (acorn woodpeckers, Melanerpes formicivorus [Hannon et al., 1985]; Arabian babblers, Turdoides squamiceps [Zahavi, 1990]; stripe-backed wrens, Campylorhynchus nuchalis [Piper and Slater, 1993]) and primates (Azara's owl monkey, Aotus azarai [Huck and Fernandez-Duque, 2012]), and fights can lead to injuries and/or eviction (Kloss's gibbon, Hylobates klossi [Tilson, 1981]; hoolock gibbon, H. hoolock [Pusey and Packer, 1987]; Azara's owl monkey [Huck and Fernandez-Duque, 2012]).

However, in some cases mature offspring may delay dispersal and use their natal territory as a "safe haven" while they wait for a breeding position to become available [Emlen, 1982; Koenig et al., 1992; Ekman et al., 2000; Kokko and Ekman, 2002]. Delayed dispersal, coupled with changing social environments following immigration, can sometimes lead to breeding opportunities within the natal group without concomitant inbreeding [Arnold, 1990; Piper and Slater, 1993; Emlen, 1995; Eikenaar et al., 2007]. If there are sufficient resources to support multiple breeders, parents may benefit by allowing their offspring to breed in their natal group, especially if the habitat is otherwise saturated with breeding pairs and offspring are unlikely to establish themselves in a new area [Emlen, 1982]. Among pair-living primates, this mating strategy may be particularly relevant for species in which there is minimal direct paternal care (i.e., no competition for care), such as gibbons (Hylobates spp. [Palombit, 1996; Rafacz et al., 2012]) and saki monkeys (Pithecia spp. [Norconk, 2011]). 
Saki monkeys are considered to be pair-living primates that also occasionally live in groups with multiple adults of one or both sexes [reviewed in Norconk and Setz, 2013; Van Belle et al., 2015; Thompson, 2016]. Sakis have been reported to retain adult offspring [Thompson et al., 2010; Norconk, 2011] and to accept putatively nonrelated adult immigrants into the group [Porter et al., 2015]. In Suriname, white-faced sakis ( $P$. pithecia) living in groups with multiple same-sex adults are argued to form "primary dyads" between particular male-female pairs [Thompson and Norconk, 2011]. Animals in putative primary dyads spend more time closer to one another and more time grooming one another than other individuals in the group, including other sexually active individuals [Thompson and Norconk, 2011]. These observations suggest that sakis, even within groups with more than 1 adult of the same sex, may form social relationships that resemble those described for other pair-living species, such as titi monkeys (subfamily Callicebinae) [Anzenberger, 1988; Fernandez-Duque et al., 1997; Lawrence, 2007]. However, animals in primary dyads do not necessarily copulate exclusively or more frequently within the dyad than do animals in nonprimary dyads. Unfortunately, studies of sakis living in such groups have not been able to distinguish additional nonrelated adults from adult offspring [Thompson and Norconk, 2011; Thompson, 2013], which complicates the interpretation of primary dyads, pair-living, and group-living. This distinction is important for understanding the range and limits of variation in saki social organization.

Here we describe the immigration of an adult male equatorial saki into a group following the departure of the previous resident adult male. At the time of immigration, the group contained an adult female, her adult daughter, her juvenile daughter, and her infant. To investigate saki social dynamics following the replacement of a pair mate (and the putative father of a female's offspring) by an immigrant male into a group with 2 adult females known to be mother and daughter, we tested the following predictions:

- P1: if primary dyads are a feature of saki social relationships in groups with multiple adults, then the immigrant male is predicted to develop a preferential affiliative relationship with one of the adult females - either the original resident female or her adult daughter - as indicated by higher rates of approaches and more time spent in proximity and grooming with one female compared to the other

- $\quad$ P2: if re-pairing leads to mating competition between the resident female and her adult daughter, then high rates of directed aggression and copulation harassment between the 2 females are predicted and, further, one of the females is predicted to become increasingly peripheralized and/or evicted from the home territory

- P3: if parental re-pairing offers a breeding opportunity for the adult daughter in her natal group, then the adult daughter is predicted to delay dispersal and begin breeding in her natal group

We analyzed nearest neighbor $(\mathrm{NN})$ data, approach interactions, grooming relationships, and rates of aggression and copulation to characterize spatial and social relationships between the 3 adult animals (defined below). We focused on interactions between adults to understand the social dynamics between potentially reproductive individuals. 


\section{Methods}

Study Site and Subjects

The field research was conducted at the Tiputini Biodiversity Station $\left(76^{\circ} 08^{\prime} \mathrm{W}, 0^{\circ} 38^{\prime} \mathrm{S}\right)$, located in the Yasuní National Park and Biosphere Reserve in eastern Ecuador. The study site comprises approximately 650 ha of primary tropical rain forest, including both várzea (periodically flooded) and terra firme (unflooded) forest.

We have been regularly monitoring the study group since November 2003 [Di Fiore et al., 2007; Fernandez-Duque et al., 2013; Porter et al., 2015; Van Belle et al., 2015]. At the time of the adult male's immigration, the group contained the original adult female present since the onset of the study (hereafter the "resident female") and her 3 offspring: a 5-year-old daughter ("adult daughter") born between November 5 and 26, 2006, a 1.5-year-old daughter ("juvenile daughter") born between March 9 and 15, 2010, and a 1-month-old infant of unknown sex born between November 15 and December 3, 2011. We classified the older daughter as an adult based on the literature on ontogeny and life history traits from both wild and captive populations of sakis [Savage et al., 1995; Norconk, 2006; Van Belle et al., 2015] and by the fact that she gave birth to an infant in late October 2012, at the age of 5.5 years. We first observed an unknown male ranging with the group on December 16, 2011, just 4 days after the previous resident male (who was the putative father of both the daughters and the infant) had left the group with another known adult male and an unknown female [Porter et al., 2015]. We again saw an unknown male with the group 1 week later, but it was unclear whether it was the same unknown male as before. By January 2, 2012, we were able to repeatedly recognize the same male (hereafter the "immigrant male") with the group, based on his unique forehead markings. The results presented here cover the period from January to December 2012.

The infant of the resident female disappeared between January 10 and 20, 2012, following the immigration of the male. All the other animals remained in the group for the duration of the study, and both the resident female and her adult daughter subsequently reproduced. The adult daughter gave birth between October 22 and 28, 2012 and the resident female between November 20 and 23, 2012 [Van Belle et al., 2015]. A study of captive Pithecia reported a mean gestation length of 146 days [Savage et al., 1995], so it is most plausible that the immigrant male sired both infants. The adult daughter disappeared from the group between March and June 2014 [Van Belle et al., 2015], leaving behind her offspring, who remains in the group until the present (January 2017).

\section{Data Collection}

In equatorial sakis, males can often be distinguished from other males by their unique and prominent forehead markings. Females, however, are more challenging to distinguish from one another since they lack these markings. Females can sometimes be distinguished by other aspects of their facial pelage, but these differences are much more subtle than the males' forehead markings. Given the difficulties of observing sakis in dense forest, we captured and radio-collared the 3 adult animals to facilitate identification and observation. The resident female was captured and radio-collared on December 5, 2007. The adult daughter was captured and radio-collared on December 28, 2011. The immigrant male was captured and radio-collared on May 30, 2012. The capture procedures followed the same protocol previously used for owl monkeys (Aotus spp.) [Fernandez-Duque and Rotundo, 2003] and sakis [Di Fiore et al., 2007].

We typically followed the animals from their morning sleeping tree to their evening sleeping tree, and we collected behavioral data throughout the day. Between January and December 2012, we conducted 356 continuous focal 20 -min assessments of individuals during 453 observation hours. Because sakis are cryptic and frequently out of view, we sampled animals opportunistically based on their visibility, but successive focal samples of the same individual were always separated by at least $20 \mathrm{~min}$. We attempted to obtain similar numbers of focal samples per individual per month (Table 1 ).

During focal samples, we conducted instantaneous point sampling every $2 \mathrm{~min}$, at which time we recorded the focal animal's $\mathrm{NN}(\mathrm{s})$. If the focal animal was out of view during an instantaneous point sample, we recorded the NN as "unknown." We collected 812 instantaneous point samples in which the NN was identified and was a single animal of interest. Between successive 2-min in- 
Table 1. Number of focal samples per individual saki monkey per month

\begin{tabular}{lccc}
\hline Month & $\begin{array}{l}\text { Resident } \\
\text { adult female }\end{array}$ & Daughter & $\begin{array}{l}\text { Immigrant } \\
\text { male }\end{array}$ \\
\hline Jan & 13 & 14 & 14 \\
Feb & 6 & 9 & 11 \\
Mar & 3 & 6 & 6 \\
Apr & 11 & 11 & 14 \\
May & 14 & 15 & 17 \\
Jun & 4 & 4 & 7 \\
Jul & 10 & 4 & 8 \\
Aug & 10 & 11 & 13 \\
Sep & 7 & 6 & 9 \\
Oct & 12 & 8 & 14 \\
Nov & 10 & 11 & 20 \\
Dec & 8 & 7 & 9 \\
\hline
\end{tabular}

stantaneous point samples, we recorded all observed occurrences of approaches (moving to within $0.5 \mathrm{~m}$ of another individual and staying for at least $3 \mathrm{~s}$ ), grooming, playing, copulating, and aggression. We also documented all observed occurrences of the above behaviors that happened outside of the focal samples and described them qualitatively. We recorded focal samples into a Dictaphone (Olympus WS-311M) and then transcribed and entered them into a Microsoft Access database.

\section{Data Analysis}

$\mathrm{NN}$ and Approach Interactions

$\mathrm{NN}$ and approach data were analyzed for each individual using log odds ratios to infer an animal's affiliation with one potential partner relative to another [Porter et al., 2015]. The log odds that the $\mathrm{NN}$ of the focal individual is animal $\mathrm{A}$, relative to animal $\mathrm{B}$, is calculated as:

$$
L O R_{A / B}=\log \left(\frac{\text { number of instantaneous point samples animal } \mathrm{A} \text { is } \mathrm{NN}+0.5}{\text { number of instantaneous point samples animal } \mathrm{B} \text { is } \mathrm{NN}+0.5}\right) \text {. }
$$

The addition of 0.5 in both the numerator and denominator is a standard boundary correction to avoid ratios involving the number zero; this correction introduces no bias towards either animal [Agresti, 1990]. Log odds ratios for approaches are defined in the same way, using the number of approaches in a focal sample. For NN and approach data, we calculated a log odds ratio for each focal sample. This treats the focal sample as the basic unit of observation. For the NN data, the log odds ratios were based on the number of instantaneous point samples that a given animal (and only that animal) was the NN. For a focal sample to be included in the NN analysis, there had to be at least 1 positive identification of a known NN. Similarly, there had to be at least 1 approach for a focal sample to be included in the approach analysis.

For the immigrant male, the ratios were calculated relative to the resident female (i.e., the resident female was always represented in the denominator). For the resident female and her adult daughter, the ratios were calculated relative to the immigrant male (i.e., the immigrant male was always represented in the denominator). Positive and negative trends in log odds ratios describe changes in affiliative interactions over time.

We used time course graphs fitted with nonparametric smoothing functions to display trends in social interactions across the study period [Porter et al., 2015]. Because log odds ratios can be highly variable, we fitted cubic splines to the time course graphs to reveal changes in affiliative behaviors over time, as suggested by trends in the log odds ratios. Periods when the spline rests on the 1:1 line (i.e., log odds ratio $=0$ ) indicate an equal tendency for the focal animal to interact with either of the 2 potential partners being compared. Areas where the spline is above 
the $1: 1$ line indicate that the focal animal's interactions are biased toward the animal in the numerator, and below the 1:1 line toward the animal in the denominator. For each graph, the $y$-axis is labeled so that, for example, 5:1 marks the level at which the focal animal is 5 times as likely to interact with one animal relative to the other.

We quantified the uncertainty in time course trends by obtaining $95 \%$ confidence bands (represented in the figures below by the shading around the spline) using 1,000 basic nonparametric bootstraps. The bootstraps resample log odds ratios with replacement within each month of observation (i.e., a stratified bootstrap with months as strata). This approach respects the approximate balance of focal sample numbers obtained for each individual during each month of observation. We detect periods during which an animal showed a statistically supported bias toward one partner relative to another by noting where the confidence bands exclude the 1:1 line. Confidence bands incorporating the 1:1 line suggest that the focal animal had no bias in affiliation toward either partner during a particular period and that this relative indifference about partners was statistically supported [Porter et al., 2015].

\section{Grooming}

We defined grooming bouts as a continuous period of one animal grooming another animal. If the focal animal changed from active groomer to receiver, or if grooming was suspended for $\geq 30 \mathrm{~s}$, we considered the bout to have ended for that individual. If the focal animal was already grooming at the beginning of the focal sample or continued grooming after the focal sample ended, we recorded the bout as "censored" to prevent artificially shortening long bouts. We used standard survival analysis methods [Cox and Oakes, 1984] to estimate how long censored bouts would have been if observed to completion, and used these estimates in the graphs when necessary (i.e., we performed conditional mean imputation). An exponential distribution proved to be a good fit for bout lengths based on the test described in section 3.7 of Cox and Oakes [1984], and this provided the conditional means. We produced for grooming data a log odds ratio for each focal sample in a similar manner as those for the $\mathrm{NN}$ and approach interactions, as follows:

$$
L O R_{A / B}=\log \left(\frac{\text { total time in minutes grooming }(\text { as actor }) \text { animal } \mathrm{A}+1 / 60}{\text { total time in minutes grooming (as actor) animal } \mathrm{B}+1 / 60}\right) .
$$

One second $(1 / 60)$ is added to both the numerator and denominator as a boundary correction. The same procedure was used for grooming bouts when the focal animal was the recipient of grooming. For a focal sample to be included in the grooming analysis, there had to be at least 1 grooming bout in the focal sample. The graphs below depict grooming ratios on a log scale, similar to the log odds of count observations for the $\mathrm{NN}$ and approach interactions. All statistical analyses were conducted with R statistical software, version 2.15.2 [R Core Development Team, 2012].

This research was done in full agreement with all Ecuadorian legislation and was approved by the Institutional Animal Care and Use Committee at the University of California, Davis (protocol No. 16117) and by the University Animal Welfare Committee at New York University (protocol No. 04-1217). Capture and collaring were essential for regularly locating the animals in their natural environment.

\section{Results}

For the entire study period, we observed no aggressive interactions between the resident female and her adult daughter, including the time after the arrival of the immigrant male. Affiliative interactions between the 2 females were infrequent, and, overall, both females interacted more with the immigrant male than they did with each other.

Throughout most of the 12 months following the male's immigration, the resident female had the immigrant male as her NN more often than her adult daughter 


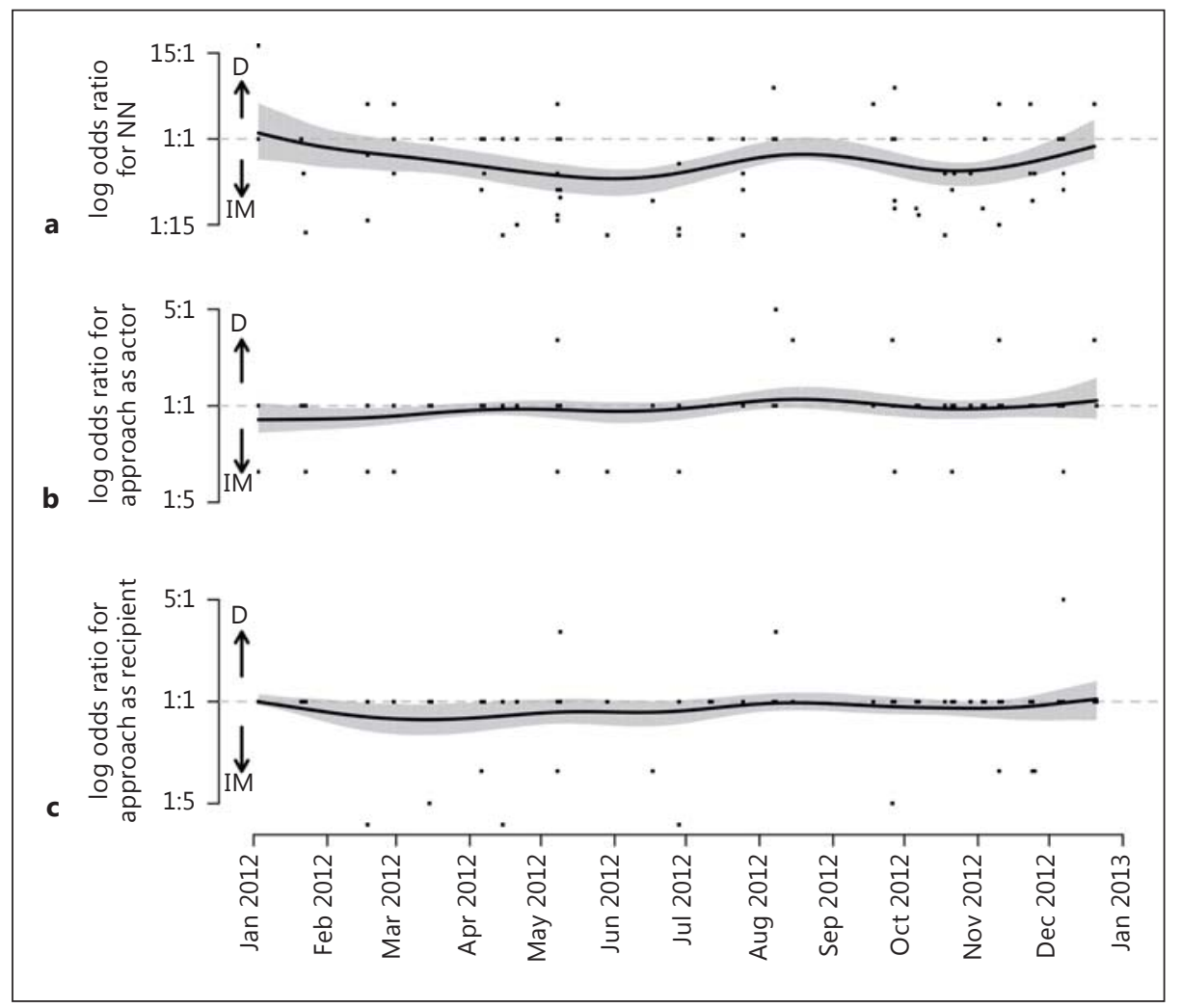

Fig. 1. Time course graphs with the log odds ratios for the resident female's NN (a), her approaches (b), and her receipt of approaches (c). For each behavior, the log odds ratios compare the adult daughter (D) relative to the immigrant male (IM); observations above the 1:1 line indicate a greater tendency for the resident female to interact with the daughter and those below with the immigrant male.

(Fig. 1a). Her approach interactions were variable, but, overall, she approached and was approached by her adult daughter and the immigrant male equally (Fig. 1b, c). Small sample size precluded analysis of the resident female's grooming bouts as the actor (grooming the immigrant male: $n=3$ events; grooming her adult daughter: $n=$ 1 event). However, she was groomed by the immigrant male consistently more often than by her adult daughter (Fig. 2).

Similarly, throughout most of the year following the male's immigration, the adult daughter had the immigrant male as her NN more often than the resident female (Fig. 3a). Within a month of his arrival, she was observed playing ( $n=6$ events) and copulating ( $n=2$ events) with him without any harassment or interference from the resident female. The adult daughter's approach interactions were variable, and from January through July, she approached and was approached by the resident female and immigrant male almost equally (Fig. 3b, c). From August through December, however, she approached and was approached by the immigrant male more often than by her mother, the resident female. Throughout the study, the adult daughter 


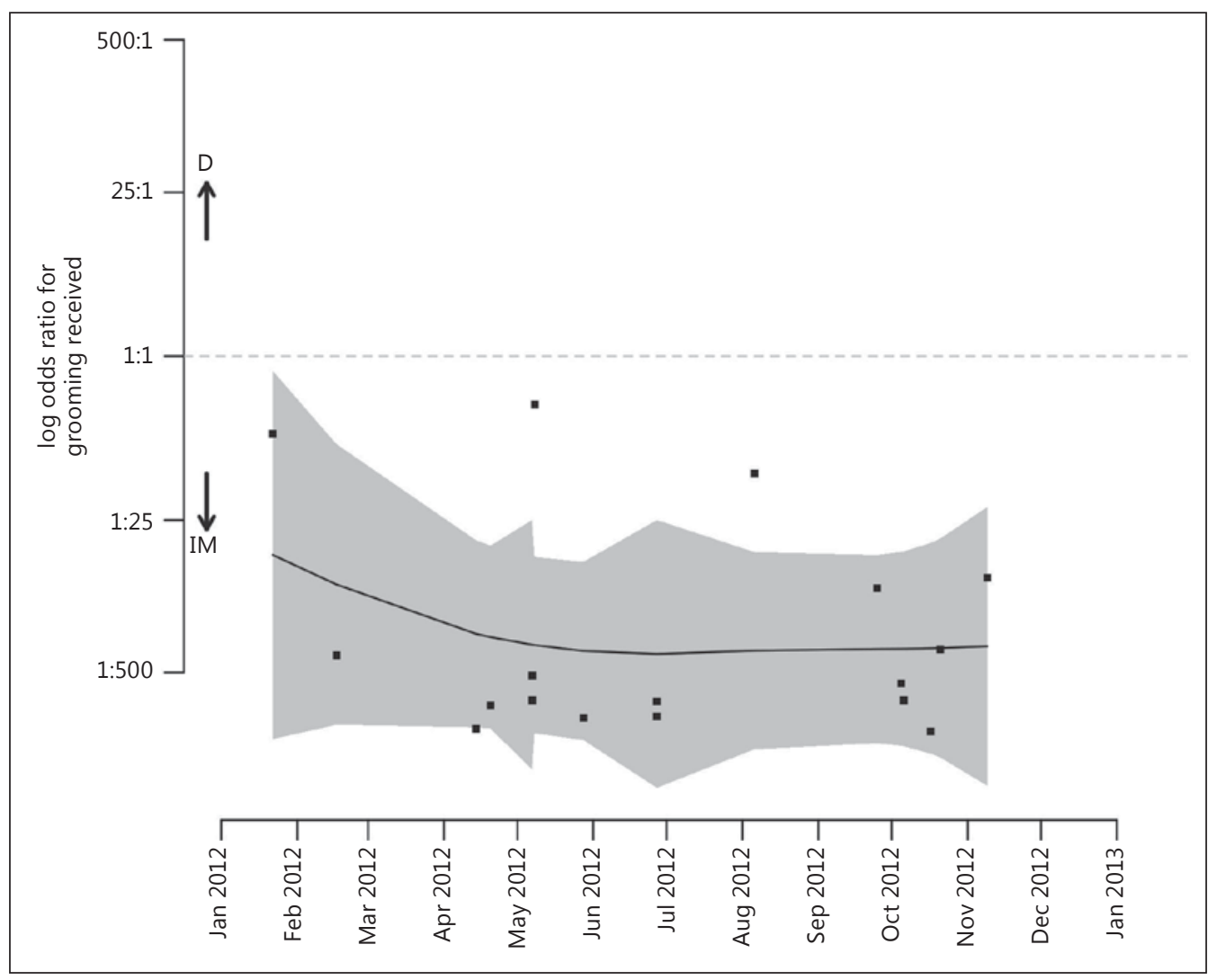

Fig. 2. Time course graphs with the log odds ratios for the resident female's receipt of grooming. The log grooming ratios compare the adult daughter (D) relative to the immigrant male (IM); observations above the 1:1 line indicate a greater tendency for the resident female to be groomed by the daughter and those below with the immigrant male. Note that the resident female groomed too infrequently for analysis of her log odds ratios as a groomer.

also spent more time grooming with the immigrant male than with the resident female, both as actor and recipient (Fig. 4a, b).

The immigrant male's affiliative interactions with the resident female and her adult daughter fluctuated over time. From January until May, the adult daughter was his NN more often than the resident female (Fig. 5a). However, in May (4 months after the loss of the resident female's infant), he began spending more time with the resident female and they copulated ( $n=1$ observed event). Then, from May through July, the resident female was his NN more often than the adult daughter (Fig. 5a). Throughout the study, however, he approached and was approached by both females almost equally (Fig. 5b, c).

The immigrant male's grooming relationships followed a similar temporal pattern as his NN data. From January until May, he spent more time grooming with the adult daughter than he did with the resident female, both as actor and recipient (Fig. 6a, b). From May until July, however, he spent more time grooming the resident 


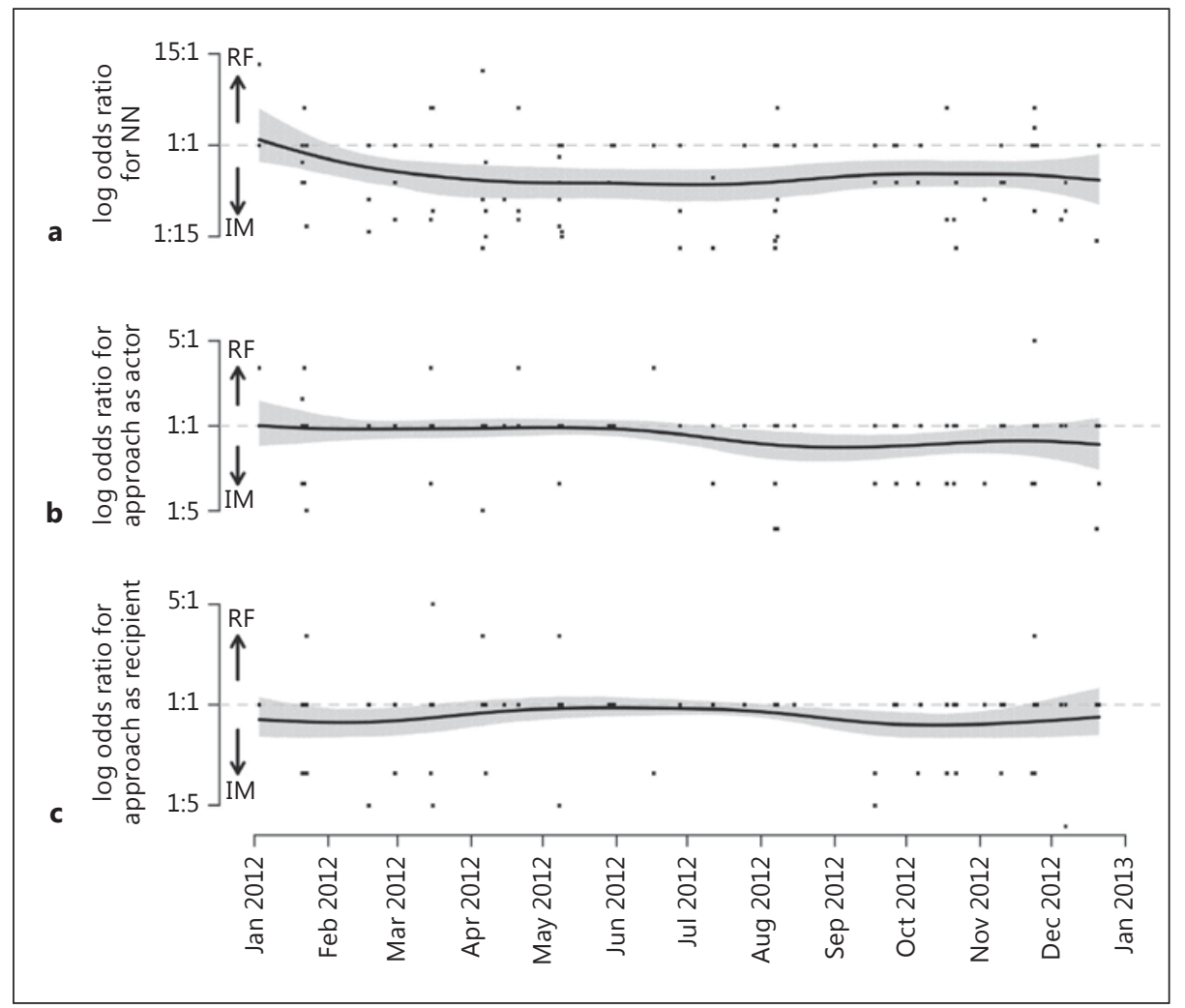

Fig. 3. Time course graphs with the log odds ratios for the adult daughter's NN (a), her approaches (b), and her receipt of approaches (c). For each behavior, the log odds ratios compare the resident female $(\mathrm{RF})$ relative to the immigrant male (IM); observations above the 1:1 line indicate a greater tendency for the adult daughter to interact with the resident female and those below with the immigrant male.

female than he did the adult daughter (Fig. 6a), although he continued to be groomed by the adult daughter more than by the resident female (Fig. 6b). From July through September, he groomed both females equally, but from October until December, he began again spending more time grooming the adult daughter (Fig. 6a). The immigrant male groomed both females more than either groomed him. He was the groomer in $65 \%$ of all the grooming interactions with the adult daughter $(n=177)$ and in $84 \%$ of all the grooming interactions with the resident female ( $n=83$ events).

\section{Discussion}

Preferential Social Bonds (Primary Dyads)

Thompson and Norconk [2011] suggest that although white-faced sakis have variable grouping patterns and mating strategies, within-group social relationships may still resemble other pair-living primates in the sense that a single male-female 


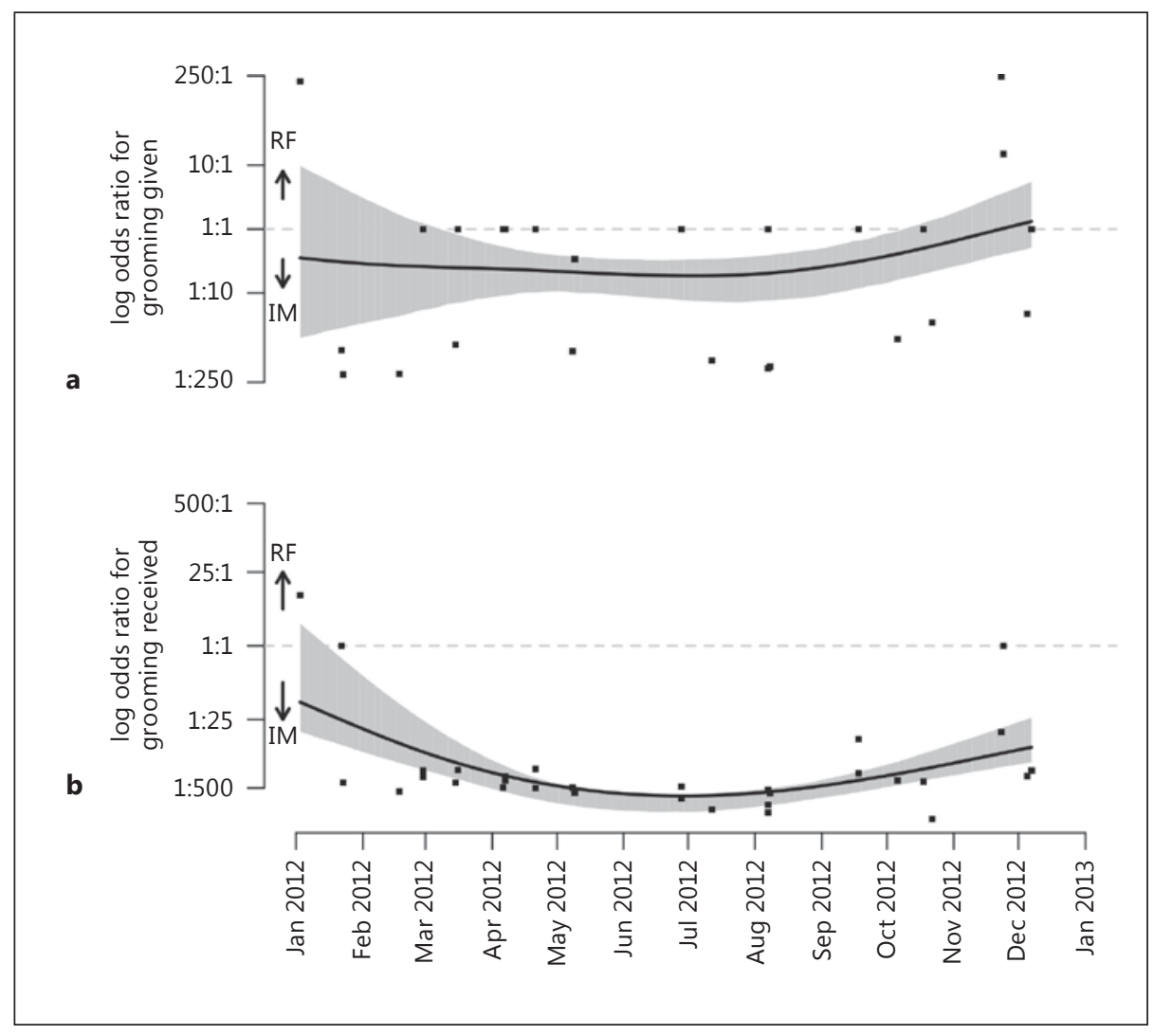

Fig. 4. Time course graphs with the log odds ratios for the adult daughter's grooming (a) and her receipt of grooming (b). The log grooming ratios compare the resident female (RF) relative to the immigrant male (IM); observations above the 1:1 line indicate a greater tendency for the adult daughter to groom with the resident female and those below with the immigrant male.

pair interacts preferentially with one another relative to other adult animals in the group. Specifically, they argue that despite the presence of multiple sexually active animals in a group, the strongest social relationship (inferred from proximity and grooming relationships, but not mating) still appears to be between a single malefemale pair (i.e., the "primary" dyad). In white-faced sakis, grooming in primary dyads is largely nonreciprocal, with the female more often being the groomer, while grooming among other male-female dyads is considerably less frequent, but more reciprocal [Thompson and Norconk, 2011].

Our first prediction that the immigrant male would develop a preferential affiliative relationship with one female - either the resident female or her adult daughter - as indicated by higher rates of approaches and more time spent in proximity and grooming, was not fully supported. Thus, it is not entirely evident that primary dyads are a feature of saki social relationships in groups with multiple adults. Rather, our study suggests that in this one group of equatorial sakis, social interactions were not 


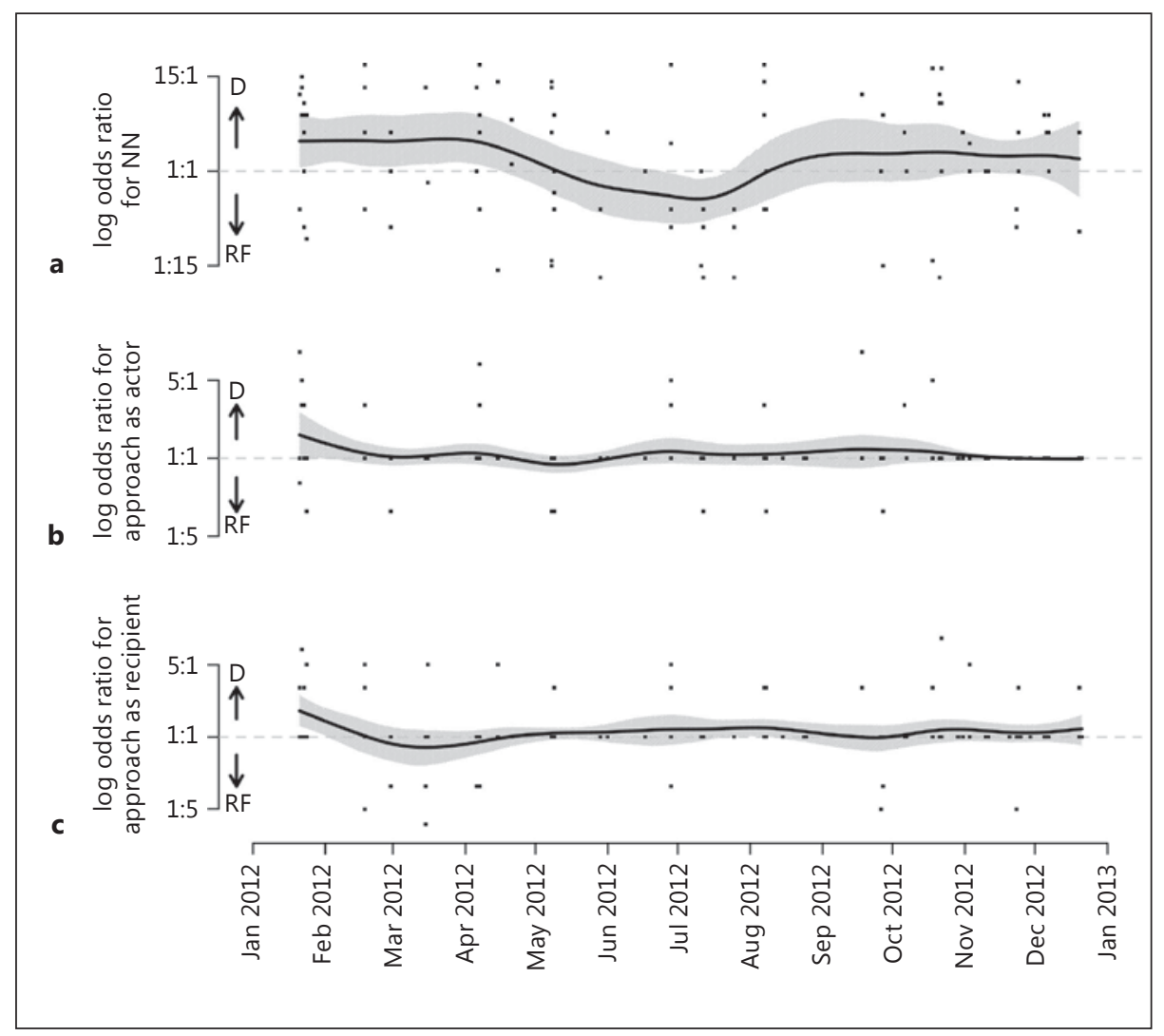

Fig. 5. Time course graphs with the log odds ratios for the immigrant male's NN (a), his approaches $(\mathbf{b})$, and his receipt of approaches $(\mathbf{c})$. For each behavior, the log odds ratios compare the adult daughter (D) relative to the resident female (RF); observations above the 1:1 line indicate a greater tendency for the immigrant male to interact with the adult daughter and those below with the resident female.

demonstrably stronger among a particular male-female pair. Even after 12 months of observation, it was not clear whether the immigrant male had formed a stronger affiliative relationship with either of the 2 adult females. Overall, the immigrant male spent more time closer to the adult daughter and more time grooming with her than he did with the resident female. However, grooming was more reciprocal between the immigrant male and the adult daughter, and for both females, the immigrant male, rather than the female, was more often the groomer. The apparent pattern was one where the immigrant male's social dynamics with each of the 2 adult females fluctuated over time.

The resident female lost her 1-month-old infant in January, soon after the immigration of the male, and she gave birth again in November. It is thus possible that the immigrant male behaved more affiliatively toward the resident female during a time when she was cycling and ovulating. Captive studies of white-faced sakis have 


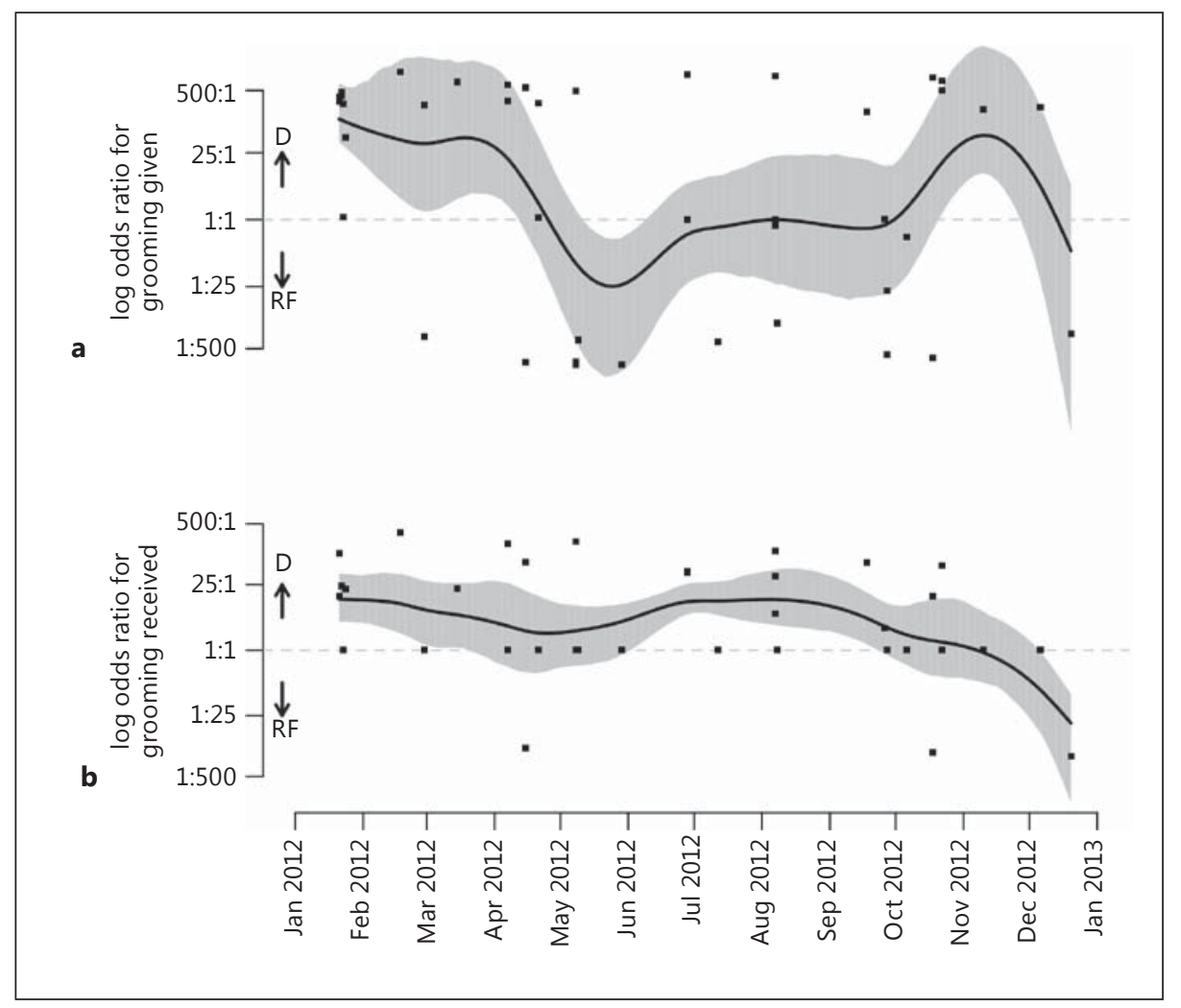

Fig. 6. Time course graphs with the log odds ratios for the immigrant male's grooming (a) and his receipt of grooming with the 2 adult females (b). The log odds grooming ratios compare the adult daughter (D) relative to the resident female (RF); observations above the 1:1 line indicate a greater tendency for the immigrant male to groom with the adult daughter and those below with the resident female.

revealed approximately 195 days of lactational amenorrhea, ovarian cycles of 16-17 days, and a gestation period of about 150 days [Shideler et al., 1994; Savage et al., 1995]. There is indirect evidence that male white-faced sakis may distinguish cycling versus noncycling females through olfactory cues [Thompson et al., 2011], and if this is supported in the future by direct evidence, the same may apply to equatorial sakis. This is a topic for the future, however, as we have no hormonal data from the animals in our study population.

The relationship between the immigrant male and the resident female may represent mainly a sexual dyad, but not a "primary dyad" sensu Thompson and Norconk [2011]. Saki monkeys appear to have a variable social organization, and comparison of their behavior at different time scales offers different results. For example, when examined over an entire year our data provide, at best, limited support for the notion that when sakis live with multiple adults, a primary dyad develops between a particular male-female pair. Evidence for this comes from the immigrant male spending 
more time closer to the adult daughter and more time grooming her relative to the resident female for the majority of the study period. However, when examined on a finer time scale, i.e., monthly, the data suggest that male-female social dynamics may be driven more by the respective reproductive cycles of the females than by the development of stronger social relationships because, as the time course figures show, affiliative patterns changed to favor the resident female during the months when she was probably in a fertile reproductive cycle.

\section{Delayed Dispersal and Alternative Routes to Breeding}

Although once considered strictly pair-living, saki monkeys are becoming recognized for variability in their grouping patterns. Multi-year studies on white-faced sakis have provided rich accounts describing their social relationships and mating patterns, but such data are limited for other species of sakis [but see Di Fiore et al., 2007; Fernandez-Duque et al., 2013; Porter et al., 2015; Van Belle et al., 2015]. Norconk and Setz [2013] suggested that white-faced sakis may represent a departure from the Amazonian species, especially in their propensity toward nonmonogamous mating strategies.

Our second prediction that there would be high rates of directed aggression and copulation harassment between the two females and that one of the females would become peripheralized and/or evicted from the home territory was not supported by our data: we observed no cases of aggression between the 2 females during the year following the male's immigration, and the adult daughter remained resident in the group for at least another 15 months after the end of this study. Our observations suggest that re-pairing did not lead to mating competition between the resident female and her adult daughter. Instead, our third prediction that the adult daughter would delay dispersal and breed in her natal group was supported, suggesting that parental re-pairing offered a breeding opportunity for the adult daughter in her natal group. Mature female offspring can sometimes delay dispersal, copulate with immigrants, and reproduce in the natal group even while the same-sex parent still resides in it. Moreover, immigrants can sometimes mate with both a resident female and her adult daughter.

Several factors may have allowed the adult daughter in our study to delay dispersal and begin breeding in her natal group. First, although daughters occasionally help mothers carry infants [Porter et al., unpubl. data], adult males do not assist in direct offspring care [Norconk, 2011], thus reducing competition between females for male care. Gibbons (Nomascus spp.), which are also considered socially monogamous and lack paternal care, have also been reported to occur occasionally in groups with multiple concurrently breeding females (Hainan gibbon, N. hainanus [Zhou et al., 2008]; Cao Vit gibbon, N. nasutus [Fan et al., 2015]; western black-crested gibbon, N. concolor [Huang et al., 2013]; southern yellow-cheeked crested gibbon, N. gabriellae [Barca et al., 2016]). In contrast, owl monkeys and titi monkeys both exhibit intense paternal care and have never been reported to have more than 1 reproductive male or female in a group. Anecdotal evidence suggests that owl monkey mothers may not be able to compensate for the loss of a male caregiver during the early stages of infant development [Huck and Fernandez-Duque, 2011], and partitioning male care among multiple females' offspring may exert a similar energetic cost. The same may also be true for titi monkeys given their similar level of paternal investment and small body size.

Second, there may have been sufficient resources within the group's territory to support 2 breeding females. Evidence for this comes from the absence of agonism between the 2 females, including competition over food items, food trees, and mating 
opportunities with the immigrant male. Moreover, both females had infants within 1 month of each other. The resident female's infant disappeared after 9 months, but the adult daughter's infant was still present in January 2017 when the group was last monitored. Equatorial sakis appear to have low rates of aggression within the group. Prior to the immigrant male's arrival (from 2009 to 2011), we observed only 3 events of aggression between the resident female and her adult daughter over food [Porter et al., unpubl. data], and, as noted above, we observed no cases of aggression between these females in the year following the male's immigration. We also observed the adult daughter copulating with a different immigrant male than the one in focus in this study (one who eventually left the home territory with the previous resident male), without copulation harassment from the resident female [Porter et al., 2015]. Finally, the juvenile female in this study also eventually became sexually active and produced an offspring in her natal group in December 2014, also within 2 weeks of her mother, the resident female [Van Belle et al., 2015]. Whether the presence of 2 breeding females on a territory is related to higher plant productivity resulting from greater soil fertility compared to where white-faced sakis live [e.g., Gentry and Emmons, 1987] would be worth considering in future research.

Emlen's [1995] "An Evolutionary Theory of the Family" predicts that families that control access to high-quality resources will be more stable than those with lowquality resources and that high-quality territories can promote prolonged philopatry, occasionally leading to sharing and/or inheritance of a breeding position. Parental facilitation of reproduction in resource-rich areas is also well documented in birds, where familial lineages can persist on the same high-quality territories for several generations [Brown, 1987; Putland and Goldizen, 2001].

Finally, the study area may be saturated with breeding pairs, thus limiting opportunities for the adult daughter to establish herself and breed in a new area. Habitat saturation can be inferred from the presence of floaters and quick invasion of territories following disappearances [Tilson, 1981], both of which have been observed at Tiputini. For example, Di Fiore et al. [2007] reported multiple unfamiliar animals being seen near this group immediately following the death of the original resident male, and an unknown male was observed ranging with the study animals only 4 days after the previous resident male had departed [Porter et al., 2015]. These possibilities again point to the need for further research to understand better the social dynamics that lead to variation in saki social organization.

\section{Acknowledgments}

This study was funded by the L.S.B. Leakey Foundation, the National Science Foundation (Doctoral Dissertation Improvement Grant No. 1155978), the American Philosophical Society, the Wenner-Gren Foundation, the UC Davis Hemispheric Institute on the Americas, and the UC Davis Evolutionary Anthropology Program to A.M.P. and by the Wenner-Gren Foundation, National Geographic Society, the L.S.B. Leakey Foundation, New York University, the New York Consortium in Evolutionary Primatology, and the University of Pennsylvania to A.F. and E.F.-D. We would like to thank the Ecuadorian government, especially the officials of the Ministerio de Ambiente for granting permission to conduct the research, and to Dr. K. Swing, Dr. D. Romo, C. Romo, and D. Mosquera of the Universidad San Francisco de Quito for logistical support at the Tiputini Biodiversity Station. We would also like to thank all our volunteer field assistants, especially Nabilah Rawji, for their support in the field. 


\section{References}

Agresti A (1990). Categorical Data Analysis. New York, Wiley \& Sons.

Anzenberger G (1988). The pairbond in the titi monkey (Callicebus moloch): intrinsic versus extrinsic contributions of the pair mates. Folia Primatologica 50: 188-203.

Arnold W (1990). The evolution of marmot sociality: I. Why disperse late? Behavioral Ecology and Sociobiology 27: 229-237.

Barca B, Vincent C, Soeung K, Nuttall M, Hobson K (2016). Multi-female group in the southernmost species of Nomascus: field observations in eastern Cambodia reveal multiple breeding females in a single group of southern yellow-cheeked crested gibbon Nomascus gabriellae. Asian Primates Journal 6: 15-19.

Barelli C, Matsudaira K, Wolf T, Roos C, Heistermann M, Hodges K, Ishida T, Malaivijitnond S, Reichard UH (2013). Extra-pair paternity confirmed in wild white-handed gibbons. American Journal of Primatology 75: 1185-1195.

Birkhead T, Moller A, Ninni P (1995). Extra-pair copulation and extra-pair paternity in birds. Animal Behaviour 49: 843-848.

Bonadonna G, Torti V, Randrianarison RM, Martinet N, Gamba M, Giacoma C (2014). Behavioral correlates of extra-pair copulation in Indri indri. Primates 55: 119-123.

Brockelman WY, Reichard UH, Treesucon U, Raemakers J (1998). Dispersal, pair formation, and social structure in gibbons (Hylobates lar). Behavioral Ecology and Sociobiology 42: 329-339.

Brown S (1987). Helping and Communal Breeding in Birds: Ecology and Evolution. Princeton, Princeton University Press.

Choudhury S (1995). Divorce in birds: a review of the hypotheses. Animal Behaviour 50: 413-429.

Cohas A, Bonenfant C, Gaillard J, Allainé D (2007). Are extra-pair young better than within-pair young? A comparison of survival and dominance in alpine marmot. Journal of Animal Ecology 76: 771-781.

Cox DR, Oakes D (1984). Analysis of Survival Data. London, Chapman \& Hall.

Davies NB (1992). Dunnock Behaviour and Social Evolution. New York, Oxford University Press.

Di Fiore A, Fernandez-Duque E, Hurst D (2007). Adult male replacement in socially monogamous equatorial saki monkeys (Pithecia aequatorialis). Folia Primatologica 78: 88-98.

Digby L, Ferrari S, Saltzman W (2011). Callitrichines: the role of competition in cooperatively breeding species. In Primates in Perspective (Campbell CJ, Fuentes A, MacKinnon KC, Bearder SK, Stumpf RM, eds.), 2nd ed., pp 91-107. New York, Oxford University Press.

Eikenaar C, Richardson D, Brouwer L, Komdeur J (2007). Parent presence, delayed dispersal, and territory acquisition in the Seychelles warbler. Behavioral Ecology 18: 874-879.

Ekman J, Bylin A, Tegelstron H (2000). Parental nepotism enhances survival of retained offspring in the Siberian jay. Behavioral Ecology 11: 416-420.

Emlen ST (1982). The evolution of helping: an ecological constraints model. The American Naturalist 119: 29-39.

Emlen ST (1995). An evolutionary theory of the family. Proceedings of the National Academy of Sciences 92: 8092-8099.

Ens B, Choudhury S, Black J (1996). Mate fidelity and divorce in monogamous birds. In Partnerships in Birds: The Study of Monogamy (Black J, Hulme M, eds.), pp 344-395. New York, Oxford University Press.

Fan PF, Bartlett T, Fei HL, Ma CY, Zhang W (2015). Understanding stable bi-female grouping in gibbons: feeding competition and reproductive success. Frontiers in Zoology 12: 1-14.

Fernandez-Duque E, Huck M (2013). Till death (or an intruder) do us part: intrasexual competition in a monogamous primate. PLoS One 8: 1-5.

Fernandez-Duque E, Rotundo M (2003). Field methods for capturing and marking azarai night monkeys. International Journal of Primatology 24: 1113-1120.

Fernandez-Duque E, Di Fiore A, de Luna G (2013). Pair-mate relationships and parenting in equatorial saki monkeys (Pithecia aequatorialis) and red titi monkeys (Callicebus discolor) of Ecuador. In Evolutionary Biology and Conservation of Titis, Sakis and Uacaris (Veiga L, Barnett A, Ferrari S, Norconk M, eds.), pp 295-302. New York, Cambridge University Press.

Fernandez-Duque E, Mason WA, Mendoza S (1997). Effects of duration of separation on responses to mates and strangers in the monogamous titi monkey (Callicebus moloch). American Journal of Primatology 43: 225-237.

Gentry AH, Emmons LH (1987). Geographical variation in fertility, phenology, and composition of the understory of Neotropical forests. Biotropica 19: 216-227.

Hannon S, Mumme R, Koenig W, Pitelka F (1985). Replacement of breeders and within-group conflict in the cooperatively breeding acorn woodpecker. Behavioral Ecology and Sociobiology 17: 303-312.

Huang B, Guan ZH, Ni QY, Orkin JD, Fan PF, Jiang XL (2013). Observation of intra-group and extragroup copulation and reproductive characters in free ranging groups of western black crested gibbon (Nomascus concolor jingdongensis). Integrative Zoology 8: 427-440. 
Huck M, Fernandez-Duque E (2012). Children of divorce: effects of adult replacements on previous offspring in Argentinean owl monkeys. Behavioral Ecology and Sociobiology 66: 505-517.

Isbell LA (2004). Is there no place like home? Ecological bases of dispersal in primates and their consequences for the formation of kin groups. In Kinship and Behavior in Primates (Chapais B, Berman C, eds.), pp 71-108. New York, Oxford University Press.

Jones MGW, Techow NMSM, Ryan PG (2012). Dalliances and doubtful dads: what determines extra-pair paternity in socially monogamous wandering albatrosses? Behavioral Ecology and Sociobiology 66: $1213-1224$.

Kinzey W (1987). Monogamous primates: a primate model for human mating systems. In The Evolution of Human Behavior: Primate Models (Kinzey W, ed.), pp 105-114. New York, State University of New York Press.

Koenig W, Pitelka F, Carmen W, Mumme R, Stanback M (1992). The evolution of delayed dispersal in cooperative breeders. Quarterly Review of Biology 67: 111-150.

Kokko H, Ekman J (2002). Delayed dispersal as a route to breeding: territorial inheritance, safe havens, and ecological constraints. The American Naturalist 160: 468-484.

Lappan S (2007). Social relationships among males in multimale siamang groups. International Journal of Primatology 28: 369-387.

Lardy S, Cohas A, Figueroa I, Allaine D (2010). Mate change in a socially monogamous mammal: evidences support the "forced divorce" hypothesis. Behavioral Ecology 22: 120-125.

Lawrence J (2007). Understanding the Pair Bond in Brown Titi Monkeys (Callicebus brunneus): Male and Female Reproductive Interests. PhD thesis, Columbia University, New York.

Morton E, Derrickson K, Stutchbury B (2000). Territory switching behavior in a sedentary tropical passerine, the dusky antbird (Cercomacra tyrannina). Behavioral Ecology 11: 648-653.

Norconk MA (2006). Long-term study of group dynamics and female reproduction in Venezuelan Pithecia pithecia. International Journal of Primatology 27: 653-674.

Norconk MA (2011). Sakis, uakaris, and titis: behavioral diversity in a radiation of primate seed predators. In Primates in Perspective (Campbell CJ, Fuentes A, MacKinnon KC, Bearder SK, Stumpf RM, eds.), 2nd ed., pp 122-139. New York, Oxford University Press.

Norconk MA, Setz E (2013). Ecology and behavior of saki monkeys (genus Pithecia). In Evolutionary Biology and Conservation of Titis, Sakis, and Uacaris (Veiga L, Barnett A, Ferrari S, Norconk M, eds.), pp 262-271. New York, Cambridge University Press.

Otter K, Ratcliffe L (1996). Female initiated divorce in a monogamous songbird: Abandoning mates for males of higher quality. Proceedings of the Royal Society of London Series B 263: 351-355.

Palombit R (1994). Dynamic pair bonds in hylobatids: implications regarding monogamous social systems. Behaviour 128: 65-101.

Palombit R (1996). Pair bonds in monogamous apes: a comparison of the siamang Hylobates syndactylus and the white handed gibbon Hylobates lar. Behaviour 133: 321-356.

Pérez-Staples D, Rodríguez C, Drummond H, Osorio-Beristain M (2013). Behavioural roles in booby mate switching. Behaviour 150: 337-357.

Piper W, Slater G (1993). Polyandry and incest avoidance in the cooperative stripe-backed wren of Venezuela. Behaviour 124: 227-247.

Porter A, Grote M, Isbell L, Fernandez-Duque E, Di Fiore A (2015). A saki saga: dynamic and disruptive relationships among Pithecia aequatorialis in Ecuador. Folia Primatologica 86: 455-473.

Pusey A, Packer C (1987). Dispersal and philopatry. In Primate Societies (Smuts B, Cheney DL, Seyfarth RM, Wrangham RW, Struhsaker TT, eds.), pp 250-266. Chicago, University of Chicago Press.

Putland D, Goldizen A (2001). Family dynasties in the Tasmanian native hen (Gallinula mortierii). Behavioral Ecology and Sociobiology 51: 26-32.

Rafacz M, Margulis S, Santymire R (2012). Hormonal correlates of paternal care differences in the Hylobatidae. American Journal of Primatology 74: 247-260.

R Core Development Team (2012). R: a language and environment for statistical computing. Vienna, R Foundation for Statistical Computing.

Savage A, Lasley BL, Vecchio AJ, Miller AE, Shideler SE (1995). Selected aspects of female white-faced saki (Pithecia pithecia) reproductive biology in captivity. Zoo Biology 14: 441-452.

Seddon N, Tobias J, Butchart S (2003). Group living, breeding behavior and territoriality in the subdesert mesite Monias benschi. Ibis 145: 277-294.

Shideler SE, Savage A, Ortuno AM, Moorman EA, Lasley BL (1994). Monitoring female reproductive function by measurement of fecal estrogen and progesterone metabolites in white-faced saki (Pithecia pithecia). American Journal of Primatology 32: 95-108.

Thompson CL (2013). Non-monogamous copulations and potential within-group mating competition in white-faced saki monkeys (Pithecia pithecia). American Journal of Primatology 75: 817-824.

Thompson CL (2016). To pair or not to pair: sources of social variability with white-faced saki monkeys (Pithecia pithecia) as a case study. American Journal of Primatology 78: 561-572. 
Thompson CL, Norconk MA (2011). Within-group social bonds in white-faced saki monkeys (Pithecia pithecia) display male-female pair preference. American Journal of Primatology 73: 1051-1061.

Thompson CL, Norconk MA, Anzelc A, Gregory LT, Hurst D, Robl N (2010). Group dynamics of freeranging white-faced sakis (Pithecia pithecia) at Brownsberg Naturepark, Suriname. American Journal of Primatology 72(suppl): 59.

Thompson CL, Whitten PL, Norconk MA (2011). Can male white-faced saki monkeys (Pithecia pithecia) detect female reproductive state? Behaviour 148: 1313-1331.

Tilson R (1981). Family formation strategies of Kloss's gibbons. Folia Primatologica 35: 259-287.

Van Belle S, Fernandez-Duque E, Di Fiore A (2015). Demography and life history of wild red titi monkeys (Callicebus discolor) and equatorial sakis (Pithecia aequatorialis) in Amazonian Ecuador: a 12-year study. American Journal of Primatology 78: 204-215.

Wolff $J$ (1993). What is the role of adults in mammalian juvenile dispersal? Oikos 68: 173-176.

Zahavi A (1990). Arabian babblers: the quest for social status in a cooperative breeder. In Cooperative Breeding in Birds: Long-Term Studies of Ecology and Behavior (Stacey PB, Koenig WD, eds.), pp 103-130. Cambridge, Cambridge University Press.

Zhou J, Wei FW, Li M, Chan BPL, Wang D (2008). Reproductive characters and mating behavior of wild Nomascus haianus. International Journal of Primatology 29: 1037-1046. 